[Forthcoming, Topics in Macroeconomics]

\title{
Sticky Prices, Coordination and Enforcement
}

\author{
John C. Driscoll \\ Harumi Ito 1 \\ Federal Reserve Board \\ Brown University and NBER
}

\begin{abstract}
Price-setting models with monopolistic competition and costs of changing prices exhibit coordination failure: in response to a monetary policy shock, individual agents lack incentives to change prices even when it would be Pareto-improving if all agents did so. The potential welfare gains are in part evaluated relative to a benchmark equilibrium of perfect, costless coordination; in practice, since agents will still have incentives to deviate from the benchmark equilibrium, coordination is likely to require enforcement. We consider an alternative benchmark equilibrium in which coordination is enforced by punishing deviators. This is formally equivalent to modeling agents as a cartel playing a punishment game. We show that this new benchmark implies that the welfare losses from coordination failure are smaller. Moreover, at the new benchmark equilibrium, prices are upwardsflexible but downwards-sticky. These last results suggest that the dynamic behavior of sticky-price models may more generally depend on the kind of imperfect competition assumed.
\end{abstract}

JEL Classification Numbers: D43, E12, E30, L13

Keywords: coordination failure, menu costs, monopolistic competition, cartel.

\footnotetext{
${ }^{1}$ Federal Reserve Board, Mail Stop 75, 20th Street and Constitution Avenue NW, Washington, DC 20009 and Department of Economics, Brown University, Box B, Providence RI 02912. email: John_Driscoll@alum.mit.edu, harumi@itosun.pstc.brown.edu. We thank Peter Ireland, John Leahy, the editor and two anonymous referees for very helpful remarks. A previous version of this paper circulated under the title "Sticky Prices, Coordination and Collusion." The views expressed here are those of the authors and not necessarily those of the Federal Reserve Board or its staff.
} 


\section{Introduction}

Price-setting models with monopolistic competition and costs of changing prices can exhibit coordination failure. In response to a monetary policy shock, individual agents may lack incentives to change prices even if all would be better off by doing so, implying that price stickiness is a symmetric Nash equilibrium(SNE).

Authors typically evaluate the welfare losses from coordination failure in part with reference to a benchmark equilibrium (called the symmetric cooperative equilibrium (SCE) by Cooper and John, 1988) in which coordination is implicitly assumed to be both costless and perfectly enforced. The latter assumption is necessary because individual agents have incentives to deviate from this equilibrium.

In this paper, we consider an alternative benchmark equilibrium in which coordination must be enforced by threat of punishment of the deviators. As one might expect, welfare losses are smaller when measured relative to this equilibrium (which we refer to as the symmetric enforced equilibrium, or SEE).

Our method of modeling enforcement closely resembles the analysis of implicit cartels in which the incentive to cheat is contained by threat of punishment (applied to macroeconomic contexts by Rotemberg and Saloner, 1986 and Rotemberg and Woodford, 1991, 1992). Hence our paper also generalizes the study of the macroeconomic effects of menu costs to forms of imperfect competition other than monopolistic competition. We find that at the SEE, prices are upwards-flexible but downwards-sticky (for small monetary shocks). This result suggests that the behavior of prices and welfare in models with sticky prices may more generally depend on the kinds of imperfect competition assumed.

The rest of the paper proceeds as follows. Section 2 reviews the results from Ball and Romer (1991)'s "yeoman farmer" model of price setting under monopolistic competition and evaluates the costs of coordination failure assuming perfect coordination is possible. Section 3 considers an equilibrium assuming that coordination must be enforced by threatening to punish deviators. Section 4 looks at the aggregate supply properties of this equilibrium. Section 5 concludes. 


\section{Review: Monopolistic Competition and Per- fect Coordination}

\subsection{Flexible Prices}

We follow Ball and Romer (1991)'s "yeoman farmer" model of price-setting.

Assume there are $N$ differentiated products indexed by $j$ produced by $N$ producer-consumers (firms) indexed by $i$, where $N$ is large. Producerconsumer $i$ consumes $C_{i j}$ of product $j(j=1,2, \ldots N)$, receiving utility of $C_{i}=\left(\sum_{j=1}^{N} C_{i j}^{\frac{\epsilon-1}{\epsilon}}\right)^{\frac{\epsilon}{\epsilon-1}}$. With labor supply $L_{i}$, her utility function is given by:

$$
U_{i}=C_{i}-\frac{\epsilon-1}{\gamma \epsilon} L_{i}^{\gamma}
$$

There is increasing marginal disutility of labor, so that $\gamma>1$, and the elasticity of substitution across goods is $\epsilon>1$. The production function is linear in labor, so that $Y_{i}=L_{i}$.

Define the aggregate price level as $P=\left[\sum_{j=1}^{N} P_{j}^{1-\epsilon}\right]^{\frac{1}{1-\epsilon}}$ where $P_{j}$ is the price of good $j$. We assume the quantity theory of money holds with unit velocity, so that $Y=\frac{M}{P} .{ }^{1}$ Then one can easily show that the demand for each good is:

$$
Y_{i}=\frac{M}{P}\left(\frac{P_{i}}{P}\right)^{-\epsilon}
$$

We may then rewrite each agent's utility as a function of the price of his or her good $P_{i}$, the aggregate price level $P$ and the money stock $M$ as:

$$
U_{i}\left(P_{i}, P, M\right)=\frac{M}{P}\left(\frac{P_{i}}{P}\right)^{1-\epsilon}-\frac{\epsilon-1}{\gamma \epsilon}\left(\frac{M}{P}\right)^{\gamma}\left(\frac{P_{i}}{P}\right)^{-\gamma \epsilon} .
$$

Now consider a price competition game in which each agent chooses its price $P_{i}$. Let $P_{i}^{*}(P, M)$ be the maximizer of the above individual utility function when the aggregate price level is $P$ and the money stock is $M$. We can show that:

$$
\frac{P_{i}^{*}(P, M)}{P}=\left(\frac{M}{P}\right)^{\frac{\gamma-1}{\epsilon(\gamma-1)+1}} .
$$

\footnotetext{
${ }^{1}$ As noted in Ball and Romer $(1990,1991)$, we can obtain this standard result either by imposing a cash-in-advance constraint and assuming as in Rotemberg (1987) that money is distributed at the beginning of the period and must be spent within the period, or by assuming money enters the utility function.
} 
We define the symmetric Nash equilibrium (SNE) to be the price level $P_{S N E}$ that solves the following equation:

$$
P_{S N E}=P_{i}^{*}\left(P_{S N E}, M\right) \quad \forall i=1,2, \ldots, N .
$$

As in Ball and Romer (1991), the solution to the above symmetric equilibrium condition yields $P_{S N E}=M$ and individual utility of $U_{S N E}=\frac{\epsilon(\gamma-1)+1}{\gamma \epsilon}$.

This equilibrium is not joint-utility maximizing. Following Cooper and John (1988), we can find the symmetric cooperative equilibrium (SCE), which is Pareto-superior to the SNE. By imposing symmetry of actions $\left(P_{i}=P\right)$, the individual utility function in (3) becomes $U_{i}=\frac{M}{P}-\frac{\epsilon-1}{\gamma \epsilon}\left(\frac{M}{P}\right)^{\gamma} \cdot P_{S C E}$ jointly maximizes the sum of individual utilities:

$$
P_{S C E}=\arg \max _{P} N\left(\frac{M}{P}-\frac{\epsilon-1}{\gamma \epsilon}\left(\frac{M}{P}\right)^{\gamma}\right) .
$$

The closed form solution to the above maximization problem is $P_{S C E}=$ $\left(\frac{\epsilon-1}{\epsilon}\right)^{\frac{1}{\gamma-1}} M$, which is lower than $P_{S N E}$ derived above. The utility level at this price is $U_{S C E}=\left(\frac{\gamma-1}{\gamma}\right)\left(\frac{\epsilon-1}{\epsilon}\right)^{-\frac{1}{\gamma-1}}$, which is greater than $U_{S N E}$. Not coincidentally, this solution fully internalize all the externalities.

By letting $P=P_{S C E}(M)$ in equation (4), we have:

$$
\frac{P_{i}^{*}\left(P_{S C E}(M), M\right)}{P_{S C E}(M)}=\left(\frac{M}{P_{S C E}(M)}\right)^{\frac{\gamma-1}{\epsilon(\gamma-1)+1}} .
$$

Since $P_{S C E}<P_{S N E}=M$ and $\gamma>1$, the above right-hand side ratio is greater than 1, implying $P_{i}^{*}\left(P_{S C E}(M), M\right)$ is larger than $P_{S C E}(M)$. Therefore, the SCE is not a Nash equilibrium because individual producers have incentive to deviate by raising prices from $P_{S C E}$.

The Pareto suboptimality result derived above is not a form of coordination failure in the sense of Cooper and John (1988), since the SNE is unique, and the SCE is not a Nash equilibrium. It is worth noting, however, that if the producer-consumers were able to coordinate, they could internalize the inefficiency arising from imperfect competition ${ }^{2}$; this would yield the socially optimal solution and maximize utility of the producer-consumers.

\footnotetext{
${ }^{2}$ One can also think of this inefficiency as arising from an aggregate demand externality (Blanchard and Kiyotaki, 1987), in which each producer-consumers's choice of price, through its effects on the price level and thus aggregate demand, affects all other producerconsumers.
} 


\subsection{Sticky Prices}

In the presence of a cost of changing prices (or menu cost) $z$, there is true coordination failure in the sense of Cooper and John (1988). Consider a change in nominal money $M$ by an amount $\omega$. As shown by many authors (including Mankiw (1985) and Ball and Romer (1990, 1991)), there is a range of values of $\omega$ for which all producers would be better off if all changed prices, but no individual producer-consumer has an incentive to do so. Hence for given values of $M_{0}$ and $\omega$ within this range, there will be a sticky-price SNE as well as a flexible-price SNE.

Let $M_{0}$ denote the initial value of the money stock. Assuming that the economy is already at the $P_{S N E}\left(M_{0}\right)=M_{0}$, we introduce a monetary shock of size $\omega$. If no producers move, an individual producer receives $U_{i}\left(M_{0}, M_{0}, M_{0}+\omega\right)$ by remaining at the original price level. ${ }^{3}$ Assuming that no other producers move their prices from $M_{0}$, the best that an individual producer can achieve is $U_{i}\left(P_{i}^{*}\left(M_{0}, M_{0}+\omega\right), M_{0}, M_{0}+\omega\right)$. If the largest achievable gain from moving is smaller than the menu cost, firms will not move, generating a hysteresis band. The width of this band is given by the values of $\omega^{+}$and $\omega^{-}$which solve the producer-consumer's decision whether changing prices would increase its utility net of the menu cost:

$$
U_{i}\left(P_{i}^{*}\left(M_{0}, M_{0} \pm \omega^{ \pm}\right), M_{0}, M_{0} \pm \omega^{ \pm}\right)-U_{i}\left(M_{0}, M_{0}, M_{0} \pm \omega^{ \pm}\right)=z,
$$

where $P_{i}^{*}$ is defined as above and we have used the result that at the SNE, $P=M$.

The criterion for determining whether all firms would be better off if they all changed prices is given by:

$$
U_{i}\left(M_{0} \pm \omega^{ \pm}, M_{0} \pm \omega^{ \pm}, M_{0} \pm \omega^{ \pm}\right)-U_{i}\left(M_{0}, M_{0}, M_{0} \pm \omega^{ \pm}\right) \geq z .
$$

We can compute the welfare costs associated with economic fluctuations in this model in two ways. The first way is to compare utility levels under the flexible-price SNE with that under the sticky-price SNE. Mankiw (1985) and Ball and Romer $(1990,1991)$ show that for small (second-order) values of $z$, this welfare loss is much greater than the loss suffered by an individual

\footnotetext{
${ }^{3}$ For the rest of this paper, we assume that the initial price level is set without any anticipation of future price chance. Thus, these monetary shocks can be considered as unanticipated shocks.
} 
producer by not adjusting. ${ }^{4}$ The second way is to compare utility levels with those of the SCE. This will also be large, for the same reason: imperfect competition implies that all of the SNE are far from the SCE. ${ }^{5}$

\section{Enforced Cooperation}

In evaluating the welfare loss from coordination failure, much of the literature surveyed by and following on from Cooper and John (1988) has used the same dual approach as in the previous section: comparing the Pareto-inferior SNEs with the Pareto-superior SNE and with the SCE. In the absence of enforcement, the SCE is not a Nash equilibrium, as individual producerconsumers have an incentive to deviate.

Hence in practice any attempt to enhance welfare by imposing an equilibrium other than the SNE will require some kind of enforcement. There might be a variety of possible institutional solutions to this problem. For any enforcement mechanism to be successful, however, it needs to curtail the individual incentive to deviate, either by artificially reducing the benefits or by increasing the costs of deviating. So, instead of defining the social optimum over all price levels, we focus on the set of 'enforced' price levels and find the optimum price level within. We will re-evaluate the welfare properties of the coordination failure using our new 'enforced' benchmark.

Our problem resembles that of the dynamic model of a price cartel. There is collective gain from cooperating, but the individual incentive to deviate needs to be contained by the threat of possible punishment. Although the entire economy is modeled as a single cartel, it is not our intention to argue that this is a good description of the current real-world economy. Instead, this is an assumption about the benchmark economy against which we calculate the welfare properties of other equilibria. ${ }^{6}$ We use a cartel because it

\footnotetext{
${ }^{4}$ For large (i.e. first-order) values of $z$, the welfare loss will be small; but such large costs of changing prices seem implausible. Ball and Romer (1990) show how the ratio of these two quantities varies with different kinds of real rigidities.

${ }^{5}$ It should also be noted that in the presence of menu costs, there will in general also be hysteresis bands around the SCE in response to monetary shocks.

${ }^{6}$ Note also that unlike traditional colluders, e.g. in the models of Rotemberg and Saloner (1986) and Rotemberg and Woodford (1991, 1992), producers here will collude to lower prices, not raise them. This arises from the fact that lowering individual prices lowers the aggregate price level and thus raise aggregate demand; hence it is a consequence of any general equilibrium imperfectly competitive model in which demand for goods depends on
} 
is simply the most generic and best-understood form of self-enforcing mechanism of cooperation under negative spillovers and strategic complementarity. It allows us to illustrate the constraint and the consequences of departing from Nash equilibrium for welfare gain.

We would also like to stress that punishment-based enforcement mechanisms have broad generality in the discussion of cooperative equilibria, beyond the cartel model we discuss in this paper. For example, an alternative institutional solution such as price controls also suffers from the same individual incentive problem of the SCE. Unless the government is able to gather information about all transaction prices, any price control is subject to individual manipulation such as black market transactions. Thus, some enforcement mechanism that curtails such individual incentives through punishment (such as legal sanctions) will be necessary. So, we focus on a cartel as one of such punishment-based enforcement mechanisms.

\subsection{The Symmetric Enforced Equilibrium (Under Flex- ible Prices)}

We define a punishment-enforced equilibrium in a game theoretic framework. We consider an infinitely repeated game in which the stage game takes the form of the static model in section 2.1. This will take the form of a dynamic game for a price cartel. Agents' actions are assumed to be observable to everyone. Again, we focus on symmetric strategies and equilibria.

In this section, we define and analyze the properties of the punishment enforced equilibrium for a fixed money level assuming no menu costs. Later in section 3.2, we re-introduce menu costs and analyze its influence on the price adjustment to money shocks in section 4 .

Given a money stock $M$, consider a price $P \in\left(P_{S C E}(M), P_{S N E}(M)\right)$. Then we have:

$$
U_{i}(P, P, M)>U_{i}\left(P_{S N E}(M), P_{S N E}(M), M\right) .
$$

Even if this price $P$ cannot be sustained as a Nash equilibrium in a stage game, it can possibly be a Nash equilibrium in an infinitely repeated game. Consider the incentive problem of agent $i$ 's pricing decision while all other agents are charging the above-mentioned price $P$. Agent $i$ considers conforming to the aggregate price level $P$ or defecting and charging $P^{*}(P, M)$

aggregate demand. 
which maximizes its stage payoff. Subsequently, the cartel will punish such a defection by imposing $P_{S N E}$, the worst possible outcome in the price game. We define the punishment $K$ to be a linear function of the missed profit opportunities, $U_{i}(P, P, M)-U_{S N E}$ :

$$
K(P, M)=\sigma\left(U_{i}(P, P, M)-U_{S N E}\right),
$$

where $\sigma$ parameterizes the harshness of the punishment. Theoretically, the worst possible punishment in a price game, as in Abreu et al. (1986), is infinitely repeating $P_{S N E}$. In this case, we can let $\sigma=\frac{\delta}{1-\delta}$ where $\delta$ is the discount rate. However, such a harsh and prolonged punishment may not be institutionally feasible in the real world. Since our purpose is to be realistic about the enforcement mechanism, we accommodate such imperfect punishment in our model by varying the value of $\sigma$. For example, the cartel may be able to impose $P_{S N E}$ for only a finite punishment period, $T$, then it will revert to $P$. In that case, we have $\sigma=\frac{\delta\left(1-\delta^{T}\right)}{1-\delta}$. From this construction, we expect $\sigma$ to increase with the length of the punishment period and the relative patience of the individuals. Later, we will examine how differences in the severity of punishment (different values of $\sigma$ ) influence the equilibrium.

$P$ can be imposed as an equilibrium of this dynamic game if the following condition is satisfied:

$$
U_{i}\left(P^{*}(P, M), P, M\right)-U_{i}(P, P, M) \leq K(P, M) .
$$

We denote the left-hand side of this inequality as $\Delta U(P, M)$, which represents the maximum gain from one-shot deviation. Hereafter, we refer to this inequality as the equilibrium condition (constraint). ${ }^{7}$ We drop the $i$ subscript because both $\Delta U(P, M)$ and $K(P, M)$ are symmetric across producers.

As in Rotemberg and Saloner (1986), the closer the cooperative price level $P$ is to $P_{S N E}$, the smaller the size of the punishment $K$. The gain from the cheating, on the other hand, is larger if the cartel's price $P$ is farther away from $P_{S N E}$.

With this punishment-enforcement mechanism at work, we define "the symmetric enforced equilibrium (SEE)" to be the price level $P_{S E E}(M)$ at

\footnotetext{
${ }^{7}$ Chari and Kehoe (1990) characterize equilibria in infinite dynamic games in which one player is much larger than the others. They develop the concept of "sustainable" equilibria; in their most prominent example of such an equilibrium, the incentive for a one-shot deviation is contained by threat of infinite punishment. This condition, given in their equation (6), is analogous to the above equilibrium condition (12).
} 
which the producers' joint utilities are maximized subject to the equilibrium condition:

$$
\begin{gathered}
P_{S E E}(M)=\arg \max _{P} N\left(\frac{M}{P}-\frac{\epsilon-1}{\gamma \epsilon}\left(\frac{M}{P}\right)^{\gamma}\right) \\
\text { s.t. } \Delta U(P, M) \leq K(P, M) .
\end{gathered}
$$

For some parameter values, the equilibrium condition will not bind for any value of $M$, and an efficient cartel will reach the $P_{S C E}$ as it was defined in the previous static game. In that case, there is no problem of enforcement and $P_{S E E}$ will be the same as $P_{S C E}$. $\left(P_{S N E}>P_{S E E}=P_{S C E}\right)$.

If, on the other hand, the equilibrium condition is binding, $P_{S E E}$ will lie between the socially optimal price $\left(P_{S C E}\right)$ and the monopolistically competitive price $P_{S N E}\left(P_{S N E}>P_{S E E}>P_{S C E}\right)$. Similarly, we can show that welfare at the SEE as measured by the representative producer-consumer utility lies in between welfare of the other two equilibria: i.e. $U_{S N E}<U_{S E E}<U_{S C E}{ }^{8}$ In this case, the welfare loss of the SNE is smaller when it is compared against the SEE, than it is against the SCE.

Moreover, as long as the equilibrium constraint binds, the more severe the punishment (the larger the value of $\sigma$ ), the greater the value of $K$ and the closer the price $P_{S E E}$ to the socially optimal $P_{S C E}$. This is a standard result in the literature on dynamic pricing games.

\subsection{Sticky Prices}

Now suppose that there is a small cost of changing prices, $z$, for each producer. We redefine the SEE under this new setup.

In the following discussion, we assume that the producers see the collective gains in coordinating their prices and enforce their cooperative strategy through the threat of punishment. That is, when there is collective gain from moving prices, but an individual producer does not conform, that is considered as a deviation and calls for punishment. In this way, we can examine the enforcement mechanism that achieves the cooperative equilibrium endogenously.

The presence of the menu costs requires some modification in the equilibrium condition (12) (or equivalently (14)). Since cheating involves changing

\footnotetext{
${ }^{8}$ As shown in Appendix A.
} 
prices, the cheater has to pay $z$ when cheating. So, the gain from cheating should be modified to be:

$$
\overline{\Delta U}(P, M)=U_{i}\left(P^{*}(P, M), P, M\right)-U_{i}(P, P, M)-z .
$$

Let $\bar{K}$ be the punishment modified accordingly. For example, if the punishment $P_{S N E}$ lasts for T periods, $\bar{K}(P, M)$ can be expressed as $\delta z+\delta^{T+1} z+$ $\sum_{t=1}^{T} \delta^{t}\left[U_{i}(P, P, M)-U_{S N E}\right] . \delta z$ and $\delta^{T+1} z$ account for menu costs incurred by moving in and out of the punishment phase. More generally, the punishment $K$ is an increasing function of $\left(U_{i}(P, P, M)-U_{S N E}\right)$ as it was in definition (11) and it co-varies with the patience of individual producers and menu costs $z$.

Thus, the symmetric enforced equilibrium price is the solution to the maximization problem in (13) subject to the following modified equilibrium condition:

$$
\overline{\Delta U}(P, M) \leq \bar{K}(P, M) .
$$

As in the flexible price case, for some values of $\epsilon, \gamma$ and $\delta$, this constraint may not bind if the punishment is harsh (i.e. if $\sigma$ is high), for any level of the money stock. We again focus our attention on parameter values for which (16) can bind.

As above, $P_{S N E}>P_{S E E}>P_{S C E}$, and it is also immediate that $U_{S N E}<$ $U_{S E E}<U_{S C E}{ }^{9}$ Thus the absolute welfare loss from being at the SNE when there are menu costs is smaller relative to the SEE than it was relative to the SEE - though of course the welfare loss from being at a sticky-price SNE relative to being at a flexible-price SNE remains the same as before.

\section{Enforced Cooperation and Aggregate Sup- ply}

We now describe the response of firms under the SEE and menu costs to monetary shocks. Although we (still) do not think that the current macroeconomy can be described as a giant implicit cartel, we believe determining the properties of the SEE to be of interest for two reasons. First, were the

\footnotetext{
${ }^{9}$ More precisely, with menu costs $z$ there will be a range of prices corresponded to the SNE, SEE and SCE. For small menu costs and reasonable choices of the other parameter values, these ranges of prices will not intersect, allowing these inequalities to hold.
} 
SEE actually implemented as a benchmark equilibrium, we would like to know its properties.

More important, while the behavior of firms under menu costs is well understood for the case of monopolistic competition, that is only one form of imperfect competition. Understanding how firms behave under a cartel may help shed light on how firms would behave more generally under other forms of imperfect competition; in particular, if firm responses to monetary shocks were quite different, that would suggest that the results under monopolistic competition may not fully generalize.

Assume that the initial level of the money stock is $M_{0}$ and the economy is already at $P_{S E E}\left(M_{0}\right)$. We investigate the behavior of the cartel when there is a permanent shock that changes the money stock from $M_{0}$ to $M_{0} \pm \omega^{ \pm}\left(\omega^{+}>\right.$ $\left.0, \omega^{-}>0\right)$. This is an unanticipated monetary shock to the extent that the initial price level $P_{S E E}\left(M_{0}\right)$ was set without any anticipation of future price changes. We investigate if the cartel is willing to adjust to the new SEE price level, $P_{S E E}\left(M_{0} \pm \omega^{ \pm}\right)$and if individual producers are willing to conform to whatever the cartel decides to do. The purpose of this exercise is to identify the case in which the incentive of the cartel and individual firms prevent the price of adjusting to the new SEE, generating a hysteresis band. Moreover, in the discussion through section 4.2 , we focus on cases in which the equilibrium constraint (16) binds at the initial money stock $M_{0}$ and the initial price level $P_{S E E}\left(M_{0}\right) .{ }^{10}$

In the following discussion, we exploit several properties of the equilibrium constraint (16). Both the incentive to cheat $\overline{\Delta U}$ and the punishment $\bar{K}$ are increasing functions of $\frac{M}{P}$. If the constraint (16) binds for some value of $M / P$, they have a single-crossing property where $\overline{\Delta U}$ eventually exceeds $\bar{K}$ for arbitrarily large values of $\frac{M}{P}$. When the equilibrium constraint (16) is binding, the SEE is at the intersection of $\overline{\Delta U}$ and $\bar{K}$. As $(M / P)$ rises above the SEE level, we have $\overline{\Delta U}>\bar{K}$. And, as $(M / P)$ falls below the SEE level, we have $\overline{\Delta U}<\bar{K}$. Finally, as long as the equilibrium constraint (16) is binding, the ratio $M / P_{S E E}(M)$ is invariant to $M$.

Since positive and negative changes in the money stock affect the constraint (16) in opposite ways, we consider each case separately. In each scenario, we look at the cartel's incentive to change the enforced price and

\footnotetext{
${ }^{10}$ If the equilibrium constraint (16) does not bind, the economy achieves the SCE, so there is no issue of coordination or enforcement. Moreover, this model generates a hysteresis in which the economy is not at the SEE. Section 4.3 discusses how the economy in such initial states respond to monetary shocks.
} 
an individual firm's incentive to conform or deviate- implying four cases in all.

\subsection{Positive Monetary Shocks}

Since the economy is already at the SEE, an increase in the money stock will push $M / P$ above the intersection of $\overline{\Delta U}$ and $\bar{K}$ and break the equilibrium constraint (16). The natural prediction is that the cartel will raise prices to $P_{S E E}\left(M+\omega^{+}\right)$, which keeps $M / P$ constant (this logic follows that of Rotemberg and Saloner, 1986, who argued that a cartel lowers its price during a boom). In this section, we check to see if this outcome is possible along with other possibilities.

In the following discussion, we carefully check if the cartel's action that pursue the collective gain is compatible with the incentives of individual producers. Once the cartel's preferred decision, to more or not to move, is decided, the cartel can impose punishment $K$ on any producers who do not conform to its decision. We check the sustainablity of such an equilibrium by examining the incentive of a single producer to conform to the cartel's decision when all other producers are already conforming. If the incentive

of this single non-conforming producer outweigh the punishment $K$, then we assume that all other firms will also deviate from the cartel's decision, thus that particular equilibrium is not sustainable. On the other hand, if the punishment outweigh the incentive to deviate, the cartel's decision can be sustained as an equilibrium.

First, we check the cartel's incentive to move its price. By moving, they will maintain $U_{S E E}$, but they have to pay the menu costs. Alternatively, they may have an option of maintaining the original price $P_{S E E}\left(M_{0}\right)$ and receiving utility level $U_{i}\left(P_{S E E}\left(M_{0}\right), P_{S E E}\left(M_{0}\right), M_{0}+\omega^{+}\right)$on the condition that individual firms conform (we check individual incentives in a moment). The cartel would like to move if the following condition holds:

$$
\frac{1}{1-\delta} U_{S E E}-\frac{1}{1-\delta} U_{i}\left(P_{S E E}\left(M_{0}\right), P_{S E E}\left(M_{0}\right), M_{0}+\omega^{+}\right)>z .
$$

This condition may or may not hold, depending on parameter values and the size of the money stock change. So, we consider both cases along with individual firms' incentives to move or not to move their prices.

1. The cartel does not want to move. Firms do not want to move. 
If (17) does not hold, the cartel has no incentive to move. Since individual producers' utilities are increasing in $\frac{M}{P}$, this is a possible outcome. Even if the cartel does not want to move, would individual firms conform to that decision? We consider the incentive of an individual firm to cheat assuming that all other firms conform to the cartel. Here, cheating means individually optimizing while all other firms are charging $P_{S E E}\left(M_{0}\right)$. The gain from this cheating is $\overline{\Delta U}\left(P_{S E E}\left(M_{0}\right), M_{0}+\omega^{+}\right)$ while the punishment that the cartel can impose is $\bar{K}\left(P_{S E E}\left(M_{0}\right), M_{0}+\right.$ $\left.\omega^{+}\right)$. Then, this firm conforms if the following inequality holds:

$$
\overline{\Delta U}\left(P_{S E E}\left(M_{0}\right), M_{0}+\omega^{+}\right)<\bar{K}\left(P_{S E E}\left(M_{0}\right), M_{0}+\omega^{+}\right) .
$$

Recall that $\overline{\Delta U}(P, M)<\bar{K}(P, M)$ binds at $\frac{M}{P}=\frac{M_{0}}{P_{S E E}\left(M_{0}\right)}$. Since $\left(M_{0}+\omega^{+}\right) / P_{S E E}\left(M_{0}\right)>M_{0} / P_{S E E}\left(M_{0}\right)$, this inequality (18) will not hold. Thus, individual firms will deviate.

This implies that not moving is not an option available for the cartel since individual firms would like to move. We can exclude this case.

2. The cartel does not want to move. Firms want to move.

Our analysis of the previous case indicates that this can happen. Positive money shocks imply that the following is true.

$$
\bar{\Delta} U\left(P_{S E E}\left(M_{0}\right), M_{0}+\omega^{+}\right)>\bar{K}\left(P_{S E E}\left(M_{0}\right), M_{0}+\omega^{+}\right)
$$

As a result, firms will deviate by changing prices, the cartel will break down, and we will return to the SNE. But this outcome implies that the cartel's choice was not between moving to the SEE or staying at the current price, as was assumed in equation (17) above, but between moving to a new SEE, if that is feasible, or moving to the SNE. We thus check below whether a new SEE is feasible, and, if so, whether the cartel would prefer to move to it instead of letting the cartel dissolve.

3. The cartel wants to move. Firms want to move.

Now, we consider a case where (17) holds. The cartel wants to move to $P_{S E E}\left(M_{0}+\omega^{+}\right)$which also keep the equilibrium constraint (16) intact. Will the firm conform? It will if its incentive to cheat is smaller than the punishment: 


$$
\begin{array}{r}
U_{i}\left(P_{S E E}\left(M_{0}\right), P_{S E E}\left(M_{0}+\omega^{+}\right), M_{0}+\omega^{+}\right) \\
-U_{S E E}+z<\bar{K}\left(P_{S E E}\left(M_{0}+\omega^{+}\right), M_{0}+\omega^{+}\right) .
\end{array}
$$

Again, the left-hand side of this inequality is smaller than $\overline{\Delta U}\left(P_{S E E}\left(M_{0}+\right.\right.$ $\left.\left.\omega^{+}\right), M_{0}+\omega^{+}\right)$. The equilibrium constraint (16) implies that this inequality is also satisfied. Thus, if the cartel wants to move, individual firms will move.

4. The cartel wants to move. Firms do not want to move.

From our discussion of the previous case, we can rule out this case. The binding equilibrium condition (16) implies that firms would like to move.

These outcomes are summarized in Table 1 below. Even if the cartel has an incentive to remain at $P_{S E E}\left(M_{0}\right)$, individual firms do not have incentives to conform to that decision. The consequence of the cartel not moving is the breakdown of the cartel and return to the SNE. On the other hand, as shown in case 3 , by moving to the new SEE, the cartel achieves $U_{S E E}$. By comparing these two outcome, we have:

$$
\frac{1}{1-\delta} U_{S N E}<\frac{1}{1-\delta} U_{S E E}
$$

For the cartel, moving in response to the positive money shock dominates not moving regardless of inequality (17). ${ }^{11}$

Thus, we rule out the SNE outcome. When there is a positive money shock, the economy will move to the new SEE, and therefore there will be no hysteresis band for a positive monetary shock when the cartel starts out at the lowest price consistent with an SEE.

\begin{tabular}{|c|c|c|c|}
\hline \multicolumn{3}{|c|}{ Table 1: Positive Monetary Shocks } \\
\cline { 3 - 4 } \multicolumn{2}{|c|}{ Cartel } \\
\hline \multirow{2}{*}{ Firms } & Do Not Want to Move & Does Not Want to Move & Wants to Move \\
\cline { 2 - 4 } & Want to Move & Ruled Out & Ruled Out \\
\hline
\end{tabular}

\footnotetext{
${ }^{11}$ Unless the difference in utilities is less than the menu cost. But, in this case, the SEE is already nearly indistinguishable from the SNE.
} 


\subsection{Negative Monetary Shocks}

The equilibrium constraint (16) will become slack as a negative money shock lowers the value of $M / P$. The cartel has an incentive to lower its price to reach $P_{S E E}\left(M_{0}-\omega^{-}\right)$. The cartel would like to move if the following condition holds:

$$
\frac{1}{1-\delta} U_{S E E}-\frac{1}{1-\delta} U_{i}\left(P_{S E E}\left(M_{0}\right), P_{S E E}\left(M_{0}\right), M-\omega^{-}\right)>z .
$$

Again, we check the four possible outcomes, interacting the cartel's incentive to move and an individual firm's incentive to move.

1. The cartel does not want to move. Firms do not want to move.

Suppose that the above inequality (22) does not hold, implying that the cartel does not want to move. This may happen when $P_{S E E}\left(M_{0}-\right.$ $\left.\omega^{-}\right)$is so close to $P_{S E E}\left(M_{0}\right)$ that the gain from moving is smaller than the menu costs involved. Next, we look at the individual incentive to conform this cartel's decision. Assuming that all other firms are charging $P_{S E E}\left(M_{0}\right)$, an individual firm's incentive to cheat is $\overline{\Delta U}\left(P_{S E E}\left(M_{0}\right), M_{0}-\omega^{-}\right)$while the possible punishment is $\bar{K}\left(P_{S E E}\left(M_{0}\right), M_{0}-\right.$ $\left.\omega^{-}\right)$. An individual firm would conform if the following inequality holds:

$$
\overline{\Delta U}\left(P_{S E E}\left(M_{0}\right), M_{0}-\omega^{-}\right)<\bar{K}\left(P_{S E E}\left(M_{0}\right), M_{0}-\omega^{-}\right) .
$$

Since $\overline{\Delta U}(P, M)<\bar{K}(P, M)$ binds at $\frac{M}{P}=\frac{M_{0}}{P_{S E E}\left(M_{0}\right)}$, for $\frac{M_{0}-\omega^{-}}{P_{S E E}\left(M_{0}\right)}$ $\left(<\frac{M_{0}}{P_{S E E}\left(M_{0}\right)}\right)$, the above inequality will hold. Thus individual firms would conform to the cartel's decision not to move.

There must be $\omega^{*}(>0)$ such that the following equality holds:

$$
\frac{1}{1-\delta} U_{S E E}-z=\frac{1}{1-\delta} U_{i}\left(P_{S E E}\left(M_{0}\right), P_{S E E}\left(M_{0}\right), M_{0}-\omega^{*}\right)
$$

This implies a hysteresis band of $\left[M_{0}-\omega^{*}, M_{0}\right]$.

2. The cartel does not want to move. Firms want to move.

From our discussion of the previous case, we can exclude this possibility. 
3. The cartel wants to move. Firms do not want to move.

Suppose now that the inequality (22) holds. Thus, the cartel would like to move. Would the individual firms conform? Assuming that all other firms conform, we investigate an individual firm's incentive not to move. By not moving, this cheating firm will gain $U_{i}\left(P_{S E E}\left(M_{0}\right), P_{S E E}\left(M_{0}-\right.\right.$ $\left.\left.\omega^{-}\right), M_{0}-\omega^{-}\right)$while moving will yields $U_{S E E}-z$. If the gain from cheating is larger than the possible punishments as shown below, the firms would not move.

$$
\begin{array}{r}
U_{i}\left(P_{S E E}\left(M_{0}\right), P_{S E E}\left(M_{0}-\omega^{-}\right), M_{0}-\omega^{-}\right)-U_{S E E}+z \\
>\bar{K}\left(P_{S E E}\left(M_{0}-\omega^{-}\right), M_{0}-\omega^{-}\right)
\end{array}
$$

However, the left-hand side of the above inequality should be smaller than $\overline{\Delta U}\left(P_{S E E}\left(M_{0}-\omega^{-}\right), M_{0}-\omega^{-}\right)$since $\overline{\Delta U}\left(P_{S E E}\left(M_{0}-\omega^{-}\right), M_{0}-\omega^{-}\right)$ is the maximum obtainable gain from cheating.

Since $\overline{\Delta U}\left(P_{S E E}\left(M_{0}-\omega^{-}\right), M_{0}-\omega^{-}\right)=\bar{K}\left(P_{S E E}\left(M_{0}-\omega^{-}\right), M_{0}-\right.$ $\left.\omega^{-}\right)$, the left-hand side of the inequality (25) should be smaller than $\bar{K}\left(P_{S E E}\left(M_{0}-\omega^{-}\right), M_{0}-\omega^{-}\right)$This implies that the inequality (25) does not hold and individual firms have incentive to move, thus we can rule out this case.

4. The cartel wants to move. Firms want to move.

When the inequality (22) does hold, the cartel would like to move. From our previous discussion, firms would conform. The economy will smoothly moves to the new SEE.

Table 2 summarizes the outcomes when the money stock decreases. When the cartel wants to move, firms will also want to move, and a new SEE will be reached. When the cartel does not want to move, the economy will exhibit hysteresis.

\begin{tabular}{|c|c|c|c|}
\hline \multicolumn{3}{|c|}{ Table 2: Negative Monetary Shocks } \\
\cline { 3 - 4 } \multicolumn{2}{|c|}{ Cartel } \\
\hline \multirow{2}{*}{ Firms } & Do Not Want to Move & Hysteresis $\left[M_{0}-\omega^{*}, M_{0}\right]$ & Ruled Out \\
\cline { 2 - 4 } & Want to Move & Ruled Out & New SEE \\
\hline
\end{tabular}


The asymmetric response of the price to positive and negative money shocks implies that the welfare loss of coordination failure, as we discussed in section 2.2, is larger for a positive money shock and smaller for a negative money shock when the SEE is used as the benchmark economy than when the SCE is used. However, this difference in welfare between positive and negative shocks is much smaller than the difference in welfare between being at an SNE and being at the SEE.

\subsection{Implications for Aggregate Supply}

We have shown that the presence of menu costs creates asymmetric responses to money shocks under the SEE. When the money stock increases, the economy will smoothly transit to the new SEE. When the money stock decreases, the SEE will exhibit hysteresis: prices will be sticky downwards.

The above analysis supposes the cartel begins at the lowest price consistent with the SEE- i.e. at the point where the equilibrium constraint (16) is binding. However, it is likely that after a series of monetary shocks, the cartel will be at some point in the interior of the hysteresis band. At such a point, both positive and negative monetary shocks, if sufficiently small, will leave the cartel within the band.

Hence in practice observed hysteresis bands may be asymmetric in either direction, or even symmetric, depend on the past sequence of shocks. But note that since a large money shock, either positive or negative, will produce a return to the SEE, it is likely that most observed hysteresis bands will be larger downwards than upwards.

The hysteresis band will be larger than those under monopolistic competition; this can be seen by comparing equation (8) with equation (24). In equation (8), which determines the size of the monopolistically competitive band, the size of the band is determined by the utility gain from a single firm deviating from the aggregate price level. In equation (24), which determines the size of the band under SEE, the size of the band is determined by the utility gain from all firms changing their prices. The aggregate demand externality implies that the utility gain will be greater in the latter case than in the former. So, a larger menu cost will be needed to produce the same size hysteresis band, or, equivalently, having the same size menu cost produces a larger hysteresis band. If the punishment is not very harsh (i.e. $\sigma$ is small), so that the equilibrium is near the SNE, the size of the hysteresis bands is small. As $\sigma$ decreases, the width of the hysteresis band diminishes 
and approaches those of the SNE.

Figure 1 plots aggregate supply, which is horizontal at the SEE. $P_{S E E}\left(M_{0}\right)$ denotes the price level for the SEE at the initial money stock $M_{0}$. $Y_{S E E}$ is the level of output corresponding to the lowest price consistent with the SEE. Note that this level of output is independent of the money stock.

As noted above, at the lowest price consistent with an SEE (corresponding to aggregate demand curve $A D_{1}$, at equilibrium point $A$ ) there is only a downwards hysteresis band; positive monetary shocks will cause prices to increase with no change in output, while small negative monetary shocks will cause output to decrease with no change in prices.

Suppose that sequences of monetary shocks push aggregate demand into the interior of the hysteresis band (aggregate demand curve $A D_{2}$ and equilibrium point $B$ ). Subsequent small monetary shocks can push output in either direction, while the price level remains unchanged

A single large negative monetary shock or a series of negative monetary shocks will push aggregate demand to the lower end of the hysteresis band (aggregate demand curve $A D_{3}$ and equilibrium point $C$ ). At this point, a further negative monetary shock (to aggregate demand curve $A D_{4}$ and equilibrium point $D$ ) will cause the price level to jump down to the new SEE level, and output up to the level implied by the SEE.

A single large positive monetary shock or a series of positive monetary shocks will push aggregate demand to a point where it will no longer intersect the old hysteresis band. At such a point (aggregate demand curve $A D_{5}$ and equilibrium point $E$ ), the price level will jump upwards to the new SEE level, while output will remain at its original level.

\subsection{Idiosyncratic Shocks}

The previous subsection assumes the existence of only one shock, an aggregate one to the money stock. Caplin and Spulber (1987) and Caplin and Leahy (1991) have shown that the neutrality of money can depend on assumptions about the money supply process, idiosyncratic shocks and the initial distribution of prices. Caplin and Leahy (1997) present a dynamic model of coordination failure with idiosyncratic shocks; they show that there is only one equilibrium, in which some producers adjust even though they know no other producer will do so. John and Wolman (1999) generalize Ball and Romer's model to a dynamic setting; they find that doing so weakens the degree of strategic complentarity to the degree that there may be no 
multiplicity of equilibria.

We may be able to extend our model to allow for idiosyncratic shocks to individual producers. However, the current price-coordination scheme cannot take account of such idiosyncratic price shocks and will simply impose the same pricing rules for all producer-consumers, yielding a degenerate crosssectional distribution of prices. ${ }^{12}$

\section{Conclusion}

Welfare implications of New Keynesian pricing models are commonly drawn in part by comparing an equilibrium under perfect effortless coordination with equilbria under coordination failure. In practice, since individual producers have an incentive to deviate from the perfect coordination equilibrium, any coordination must be enforced. In this paper, we propose an alternative benchmark for evaluating the welfare loss from the coordination failure by focusing on the set of 'enforced' price levels. In order to find the optimum within such a set, we employ a model of an implicit cartel, as in Rotemberg and Saloner (1986). Our new benchmark, the symmetric enforced equilibrium (SEE) is a punishment-enforced price coordination equilibrium that lies between the monopolistically competitive, symmetric Nash equilibrium (SNE) and the symmetric cooperative equilibrium (SCE).

We re-evaluate the welfare loss of coordination failure under our benchmark. It remains true that difference in utility between the sticky-price SNE and the flexible price SNE is large relative to the utility loss suffered by an individual producer-consumer by not adjusting. However, the absolute loss in utility is smaller relative to the SEE than to the SCE, since the SEE's utility level is lower than the SCE. Depending on how harsh the punishment may be, the absolute loss may itself be quite small (i.e. zero to first-order).

We also study the aggregate supply curve implied by the SEE, not only because the latter is the constrained social optimum, but also because doing so may shed light on how aggregate supply behaves under other forms of imperfect competition than monopolistic competition. Aggregate sup-

\footnotetext{
${ }^{12}$ The recent paper by Athey et. al. (2003) has drawn a rich set of a dynamic model implications into static cartel models. It shows that the degree of patience influences the price rigidity. An impatient cartel will move prices in order to attenuate the incentive to cheat as in Rotemberg and Saloner (1986), while a patient cartel will follow a rigid-pricing scheme.
} 
ply is horizontal at the minimum price consistent with the SEE. Prices are upwardly-flexible, but downwardly rigid for small monetary shocks. A large negative monetary shock will cause aggregate supply to shift downwards, with prices moving downwards and output returning to the SEE level.

The coordination failure problem is unlikely to be solved by fiat, but rather by developing mechanisms or institutions designed to address it. Moreover, the problem itself in the context of price-setting has so far only been studied under monopolistic competition. This paper takes first steps in the directions of widening the kinds of imperfectly competitive models under which the problem is considered and in thinking more concretely about how coordination might be implemented. 


\section{A Theorems on Symmetric Enforced Equi- librium (SEE)}

Recall that utility is defined as:

$$
U_{i}=\frac{M}{P}-\frac{\epsilon-1}{\gamma \epsilon}\left(\frac{M}{P}\right)^{\gamma}
$$

and denote the price under the SNE as $P_{S N E}=M$ and under the SCE as $P_{S C E}=\left(1-\frac{1}{\epsilon}\right)^{\frac{1}{\gamma-1}} M<P_{S N E}$.

Note that this implies that:

$$
U_{S N E}=1-\frac{1}{\gamma}-\frac{1}{\gamma \epsilon}
$$

and

$$
U_{S C E}=\left(1-\frac{1}{\gamma}\right)\left(1-\frac{1}{\epsilon}\right)^{-\frac{1}{\gamma-1}}>U_{S C E} .
$$

$P_{S E E}$ is defined as in equation 14. Note that at the SNE, the incentive to cheat $\Delta U=0$ and at the SCE, $\Delta U>0$. Also, $\frac{\partial U_{i}}{\partial P_{C}}<0$ at the SCE and $\frac{\partial U_{i}}{\partial P_{C}}<0=0$ at the SNE.

Theorem $1 P_{S C E} \leq P_{S E E} \leq P_{S N E}$.

Proof: Suppose $K$ is smaller than the value $K^{*}=\Delta U\left(P_{S C E}\right)$, but larger than zero.

Suppose the resulting $P_{S E E}<P_{S C E}$. Then $\Delta U\left(P_{S E E}>\Delta U\left(P_{S C E}\right)>K\right.$. But this contradicts the definition of $P_{S E E}$.

Suppose the resulting $P_{S E E}>P_{S N E}$. Then $U_{S E E}<U_{S N E}$, but SNE is feasible. This again contradicts the definition of $P_{S E E}$.

Suppose the resulting $P_{S E E}=P_{S N E}$. Then there is a $P^{*}$ which still satisfies the equilibrium constraint but has higher utility that $P_{S E E}$ or $P_{S N E}$. This again contradicts the definition of $P_{S E E}$.

So, $P_{S C E} \leq P_{S E E} \leq P_{S N E}$.

Theorem $2 U_{S C E} \geq U_{S E E} \geq U_{S N E}$.

Proof: Follows immediately from first proposition and fact that $\frac{\partial U}{\partial P}<0$. 


\section{References}

Abreu, Dilip, David Pearce and Ennio Stacchetti. "Optimal Cartel Equilibria with Imperfect Monitoring." Journal of Economic Theory 39(1), 1986, pp. 251-269.

Athey, Susan, Kyle Bagwell and Chris Sachirico. "Collusion and Price Rigidity." Forthcoming, Review of Economic Studies, 2003.

Ball, Laurence and David Romer. "Real Rigidities and the Nonneutrality of Money." Review of Economic Studies, 57(1), 1990, pp. 183-203.

— — and — - "Sticky Prices as Coordination Failure." American Economic Review, 81(3), 1991, pp. 539-552.

Caplin, Andrew and John Leahy. "State-Dependent Pricing and the Dynamics of Money and Output." Quarterly Journal of Economics 103(3), 1991, pp. 683-708.

_ - and _ - "Aggregation and Optimization with State-Dependent Pricing." Econometrica 65(30), 1997, pp. 601-625.

— - and Daniel Spulber. "Menu Costs and the Neutrality of Money." Quarterly Journal of Economics 102(4), 1987, pp. 703-726.

Chari, V. and Patrick Kehoe. "Sustainable Plans." Journal of Political Economy 98(2), 1990, pp. 783-801.

Cooper, Russell and Andrew John. "Coordinating Coordination Failures in Keynesian Models." Quarterly Journal of Economics, 103(3), 1988, pp. 441-463.

John, A. Andrew, and Alexander Wolman "Does State-Dependent Pricing Imply Coordination Failure?" Working Paper, Federal Reserve Bank of Richmond, August 1999.

Mankiw, N. Gregory. "Small Menu Costs and Large Business Cycles: A Macroeconomic Model of Monopoly." Quarterly Journal of Economics, 100(2), 1985, pp. 529-539.

Rotemberg, Julio J. "The New Keynesian Microfoundations." NBER Macroeconomics Annual, 1987, pp. 69-104.

— — and Garth Saloner. "A Supergame-Theoretic Model of Price Wars during Booms." American Economic Review, 76(2), 1986, pp. 390-407. 
- - and Michael Woodford. "Markups and the Business Cycle." NBER Macroeconomics Annual, 1991, pp. 63-129.

- - and - - "Oligopolistic Pricing and the Effects of Aggregate Demand on Economic Activity." Journal of Political Economy, 100(6), 1992, pp. 1153-1207. 
Figure 1

Aggregate Supply for the Symmetric Enforced Equilibrium (SEE)

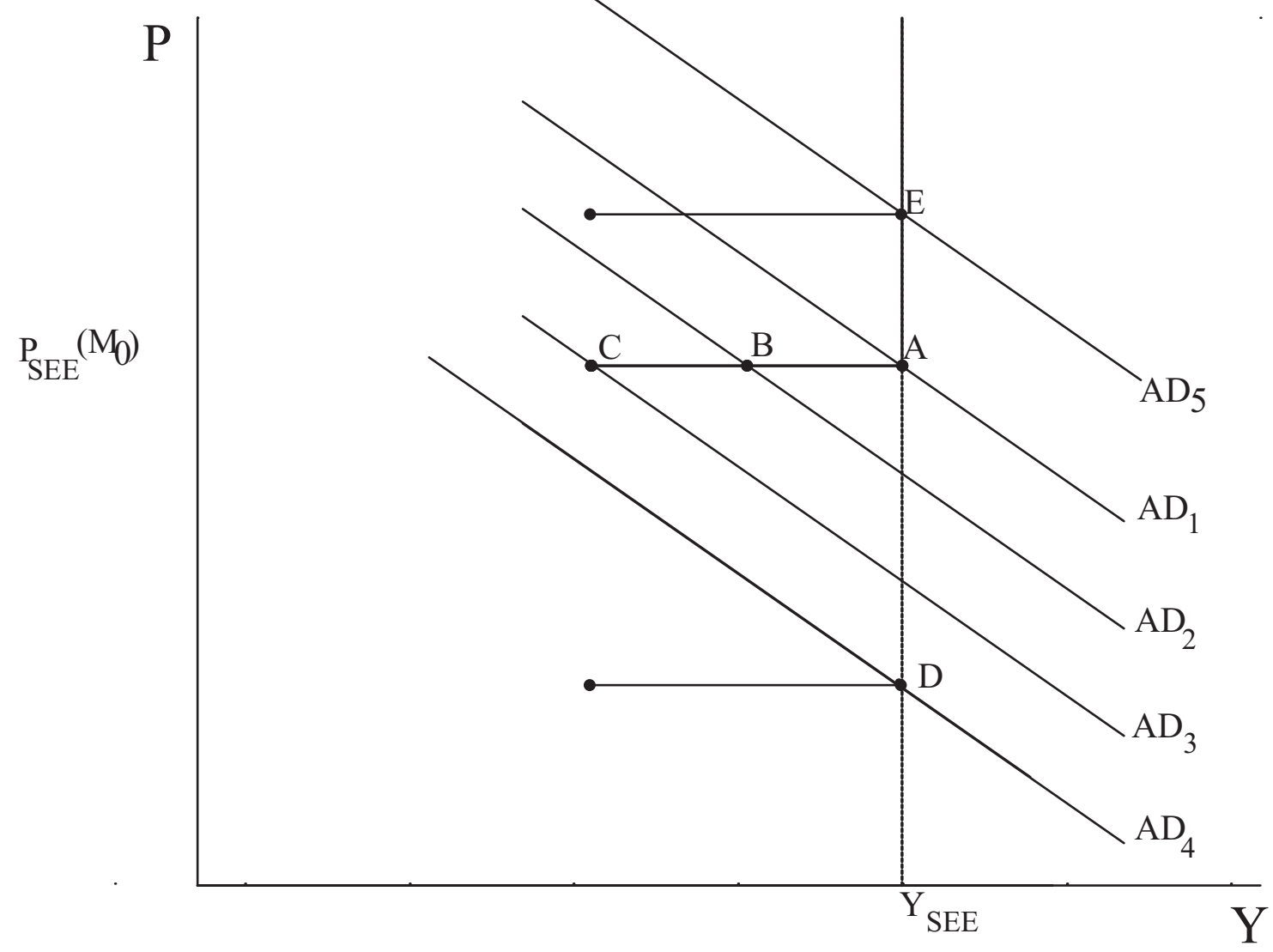

